\title{
Safety and Efficacy of Memantine in Children with Autism: Randomized, Placebo-Controlled Study and Open-Label Extension
}

\author{
Michael G. Aman, PhD, ${ }^{1}$ Robert L. Findling, MD, MBA, Antonio Y. Hardan, MD, Robert L. Hendren, DO, \\ Raun D. Melmed, MD, Ola Kehinde-Nelson, BA, ${ }^{6 *}$ Hai-An Hsu, PhD, ${ }^{6 \star \star}$ Joel M. Trugman, MD, \\ Robert H. Palmer, PhD, ${ }^{6 * \star}$ Stephen M. Graham, $\mathrm{PhD}^{6 \dagger}$ Allyson T. Gage, PhD, ${ }^{6 \dagger \dagger}$ \\ James L. Perhach, PhD, FCP, ${ }^{6+\dagger}$ Ephraim Katz, PhD ${ }^{6:}$
}

\begin{abstract}
Objective: Abnormal glutamatergic neurotransmission is implicated in the pathophysiology of autism spectrum disorder (ASD). In this study, the safety, tolerability, and efficacy of the glutamatergic $N$-methyl-D-aspartate (NMDA) receptor antagonist memantine (once-daily extended-release [ER]) were investigated in children with autism in a randomized, placebo-controlled, 12 week trial and a 48 week open-label extension.

Methods: A total of 121 children 6-12 years of age with Diagnostic and Statistical Manual of Mental Disorders, 4th ed., Text Revision (DSM-IV-TR)-defined autistic disorder were randomized (1:1) to placebo or memantine ER for 12 weeks; 104 children entered the subsequent extension trial. Maximum memantine doses were determined by body weight and ranged from 3 to $15 \mathrm{mg} / \mathrm{day}$. Results: There was one serious adverse event (SAE) (affective disorder, with memantine) in the 12 week study and one SAE (lobar pneumonia) in the 48 week extension; both were deemed unrelated to treatment. Other AEs were considered mild or moderate and most were deemed not related to treatment. No clinically significant changes occurred in clinical laboratory values, vital signs, or electrocardiogram (ECG). There was no significant between-group difference on the primary efficacy outcome of caregiver/parent ratings on the Social Responsiveness Scale (SRS), although an improvement over baseline at Week 12 was observed in both groups. A trend for improvement at the end of the 48 week extension was observed. No improvements in the active group were observed on any of the secondary end-points, with one communication measure showing significant worsening with memantine compared with placebo $(p=0.02)$ after 12 weeks.

Conclusions: This trial did not demonstrate clinical efficacy of memantine ER in autism; however, the tolerability and safety data were reassuring. Our results could inform future trial design in this population and may facilitate the investigation of memantine ER for other clinical applications.
\end{abstract}

Keywords: memantine extended release; autistic disorder; tolerability, safety, and adverse events; core symptoms of autism; Social Responsiveness Scale; Children's Communication Checklist-2

\footnotetext{
${ }^{1}$ The Nisonger Center, Ohio State University, Columbus, Ohio.

${ }^{2}$ Kennedy Krieger Institute, Johns Hopkins University, Baltimore, Maryland.

${ }^{3}$ Department of Psychiatry and Behavioral Sciences, Stanford University, Stanford, California.

${ }^{4}$ Department of Psychiatry, University of California, San Francisco, California.

${ }^{5}$ Southwest Autism Research \& Resource Center, Phoenix, Arizona.

${ }^{6}$ Forest Research Institute, (now Allergan) Jersey City, New Jersey.

*Current affiliation: Independent Industry Consultant.

**Current affiliation: Celgene Corp. Berkeley Heights, New Jersey.

***Current affiliation: Independent Industry Consultant, current consultant to the study sponsor.

${ }^{\dagger}$ Current affiliation: Newron Pharmaceuticals US Inc., Morristown, New Jersey.

Current affiliation: StemCells Inc., Newark, California.

Current affiliation: The Llessac Group LLC, Wilmington, Delaware.

Current affiliation: Independent International and Domestic Industry Consultant.

Funding: This study was supported by funding from Forest Laboratories, LLC, (Jersey City, New Jersey), Allergan. The study sponsor was involved in the study design, data collection (via contracted clinical investigator sites), analysis and interpretation of data, and the decision to present these results.

(C) Michael G. Aman et al. 2017; Published by Mary Ann Liebert, Inc. This article is available under the Creative Commons License CC-BY-NC (http://creativecommons.org/licenses/by-nc/4.0). This license permits non-commercial use, distribution and reproduction in any medium, provided the original work is properly cited. Permission only needs to be obtained for commercial use and can be done via RightsLink
} 


\section{Introduction}

$\mathbf{M}$ ETHODOLOGICALLY SOUND ANALYSES estimate the prevalence of autism spectrum disorder (ASD) (American Psychiatric Association 2000) at 60-70 children per 10,000 (i.e., at 0.6-0.7\%) (Fombonne 2009; Elsabbagh et al. 2012,); in addition, the prevalence appears to have increased over the past decades (Rosenberg et al. 2009). In children with ASD, risperidone and aripiprazole can be used to treat the associated symptoms of irritability, aggression, self-injury, temper tantrums, and mood swings (McCracken et al. 2002; Curran 2011). However, no medications are currently approved for treating the core domains of ASD (impaired social communication and interaction, and stereotyped behaviors and restricted interests), which represents a challenging unmet medical need (Mohiuddin and Ghaziuddin 2013; Rossi et al. 2013; Yudell, et al. 2013).

Glutamate is the principal excitatory neurotransmitter in the brain, and several lines of evidence implicate aberrant glutamatergic neurotransmission in the pathophysiology of ASD (Choudhury et al. 2012). For example, increased glutamate levels in plasma samples have been observed in children with ASD (Moreno-Fuenmayor et al. 1996). Also, levels of glutamate decarboxylase, the enzyme responsible for conversion of glutamate to $\gamma$-aminobutyric acid (GABA), were found to be lower in the postmortem brain tissue of patients with ASD (Fatemi et al. 2002). Levels of the glutamatergic $N$-methyl-D-aspartate (NMDA) receptor, which is instrumental for learning and formation of memory, have been shown to be high in the postmortem brain tissue of individuals diagnosed with ASD (Wenk et al. 1993; Blue et al. 1999; Purcell et al. 2001). Further, cellular abnormalities such as reduced neuronal cell size, increased cell packing density, and decreased complexity and arborization of pyramidal cells in the limbic system and reduced number of Purkinje cells in the cerebellum are consistently observed in the postmortem brain tissue of individuals diagnosed with ASD (Bauman and Kemper 2005); these abnormalities are located in brain regions where NMDA receptors are abundant (e.g., the hippocampus and cerebellum) (Collingridge and Watkins 1994).

Memantine is a moderate-affinity, uncompetitive NMDA receptor antagonist with strong voltage dependency and rapid blocking/ unblocking kinetics (Danysz and Parsons 2012) that is approved for the treatment of moderate to severe Alzheimer's disease (AD) (Namenda XR 2010). In randomized, placebo-controlled trials in patients with $\mathrm{AD}$, memantine was shown to improve functional communication (Tocco et al. 2014). In addition, data from pediatric studies have suggested good tolerability and potential clinical benefits of memantine in children with ASD. For example, 8 weeks of memantine treatment (10 or $20 \mathrm{mg}$ once daily) in 16 children (6-12 years of age) with attention-deficit/hyperactivity disorder (ADHD) required no dose reduction, and there were no adverse events (AEs) leading to discontinuation or potentially clinically significant (PCS) changes in other measures of safety (hematology, vital signs, electrocardiogram [ECG]) (Findling et al. 2007). Further, prospective and retrospective open-label studies suggested that memantine can improve social interaction and communication in children with ASD (Owley, et al. 2006; Chez et al. 2007; Erickson et al. 2007) and a 10 week randomized trial in children with autism demonstrated significant benefits of risperidone plus memantine over risperidone plus a placebo on the Irritability, Stereotypic Behavior, and Hyperactivity/Noncompliance subscales of the Aberrant Behavior Checklist (ABC) (Ghaleiha et al. 2013).

We report here the results of a randomized, placebo-controlled, proof-of-concept, phase I-II study and its open-label extension (OLEX), which investigated the efficacy, safety, and tolerability of memantine extended-release (ER) in children with autism. The efficacy hypothesis was that memantine ER treatment would improve social interaction and communication in children with autism.

\section{Methods}

\section{Study design}

The two studies described here were conducted at multiple centers in the United States between April, 2009 and February, 2013 in children diagnosed with autistic disorder, defined at the time of the study using Diagnostic and Statistical Manual of Mental Disorders, 4th ed., Text Revision (DSM-IV-TR) criteria (American Psychiatric Association 2000).

The first study, MEM-MD-57A Part 2 (NCT00872898), was a 12 week, randomized, double-blind, placebo-controlled, parallel-group, flexible-dose (first 8 weeks) and target dose $(3-15 \mathrm{mg} /$ day) trial conducted to determine safety, tolerability, and efficacy of memantine ER in children with autism. The daily dosage of memantine ER to be administered was based on weight groups: 1) Group A, $\geq 60 \mathrm{~kg}$, maximum dose of $15 \mathrm{mg} /$ day; 2) Group B, 40-59 kg, maximum of $9 \mathrm{mg} / \mathrm{day}$; 3) Group C, 20-39 kg, maximum of $6 \mathrm{mg} / \mathrm{day}$; and 4) Group D, $<20 \mathrm{~kg}$, maximum of $3 \mathrm{mg} /$ day. These maximum dose limits were selected to ensure that the plasma exposure to memantine (the area under the curve [AUC] of plasma concentration versus time) remained below the predefined safety limit, which represented a 10fold lower exposure than the no-observed-adverse-effect-level (NOAEL) established in juvenile rat studies. Two preceding pharmacokinetic (PK) dose-finding studies were completed in children with ASD and other pathologies (MEM-PK-21 and MEM-MD-57A Part 1; results not reported here) to establish the PK parameters, safety, and tolerability of these doses for the weight groups. Although we reference these PK protocols, no data from the PK subjects are presented in this report, with the exception of tolerability measures. All study medication during MEM-MD-57A Part 2 was administered in a single daily dose ( $3 \mathrm{mg}$ or $6 \mathrm{mg}$ memantine ER capsules; up to three capsules) taken orally, preferably at the same time each day of the study. Dosages of memantine ER were uptitrated from $3 \mathrm{mg} /$ day to the target doses of 3-15 mg/day.

MEM-MD-57A Part 2 was a phase II trial in which the participants were randomized 1:1 to receive placebo or memantine ER in accordance with the United States Food and Drug Administration (FDA) Guidance for Industry (United States Food and Drug Administration 2000). The randomization codes were generated and securely retained by the Statistical Programming and Drug Safety Surveillance Department at Forest Research Institute, Inc. Following 2 weeks of single-blind placebo treatment, memantine ER treatment was initiated at a dosage of $3 \mathrm{mg}$ per day and uptitrated for $\leq 8$ weeks (depending upon the weight group), which allowed for $\geq 4$ weeks of maintenance treatment at a target dose (14 weeks total, including 2 weeks of single-blind placebo).

The OLEX study (MEM-MD-67; NCT01999894) was a 48 week, multicenter trial that evaluated the long-term safety and tolerability of memantine ER in the same children. All participants who completed the lead-in study MEM-MD-57A Part 2 were eligible to enroll. The study consisted of a 6 week, double-blind, dosetitration period followed by a 42 week open-label maintenance period. The double-blind dose titration permitted the participants who were randomized to receive placebo in the lead-in study to be uptitrated to their weight-based target dosage and permitted those who were randomized to receive memantine ER to maintain their previous dosage without compromising the lead-in study blind. (Participants retained their randomization codes from the lead-in 


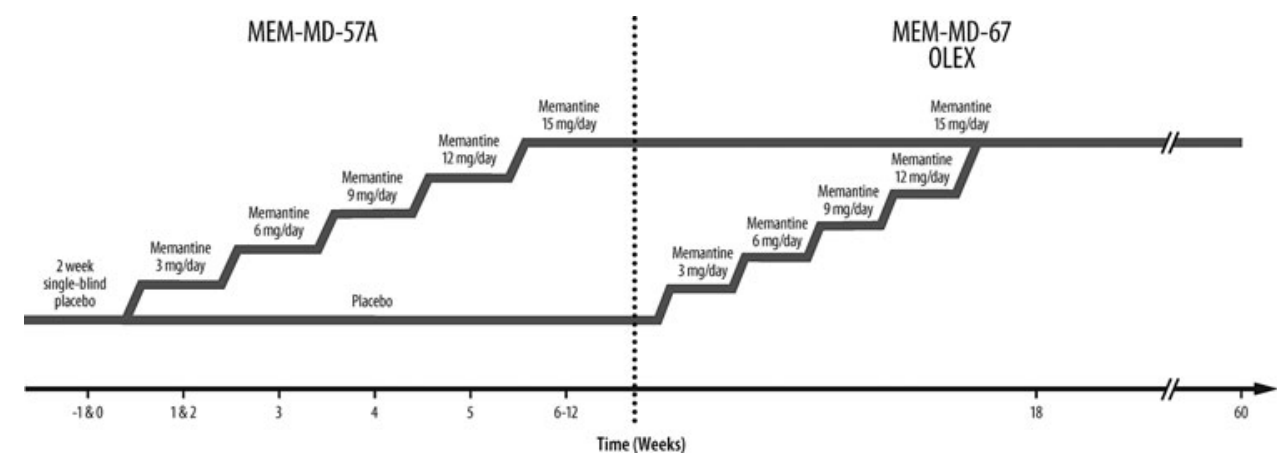

FIG. 1. Combined study design and dosing for MEM-MD-57A Part 2 and the open-label extension (OLEX). Dose titration in MEMMD-67 only for participants who were previously randomized to placebo. Participants taking memantine ER during MEM-MD-57A continued with same dose.

study; the protocol required maintaining the double blind for the first 6 weeks of the extension trial, during which memantine ER dosages were either uptitrated [in children previously assigned to placebo] or maintained [in children previously treated with memantine]). The study design and dosing for MEM-MD-57A Part 2 and the OLEX are shown in Figure 1.

\section{Participants}

Participants in MEM-MD-57A Part 2 were children 6-12 years of age who met the DSM-IV-TR (American Psychiatric Association 2000) criteria for autistic disorder based on a clinical evaluation and information derived from modules 2 and 3 of the Autism Diagnostic Observation Schedule (ADOS) (Gotham et al. 2008) and the Autism Diagnostic Interview-Revised (ADI-R) (Lord et al. 1994). Participants were also required to have: 1) Verbal fluency of at least three-word phrases in English, 2) ABCCommunity (ABC-C) (Aman et al. 1985) irritability subscale score $<17$ (in order to minimize manifestations of irritability during the study), 3) Social Responsiveness Scale (SRS) (Constantino and Gruber 2005) raw total score $>44$ (girls) or $>53$ (boys), and 4) intelligence quotient (IQ) $\geq 50$ on the Kaufman Brief Intelligence Test, Version 2, which denotes an IQ in the range of mild intellectual disability to normal ability. Inclusion criteria for the OLEX study were the completion of MEM-MD-57A Part 2, normal physical examination and laboratory test results at the first study visit of the OLEX study or the final visit of MEM-MD-57A Part 2 (if within 14 days), and negative urine pregnancy test results for girls $\geq 9$ years of age. Participants who completed the PK studies MEM-MD-57A Part 1 or MEM-PK-21, which included children and adolescents 5-16 years of age diagnosed with autistic disorder (DSM-IV-TR), who did not fulfill the inclusion criteria for Part 2, were also eligible for enrollment in the OLEX at the investigator's discretion, to provide compassionate care for those individuals. Data for these subjects were not included in this report.

Exclusion criteria for MEM-MD-57A Part 2 were premature birth (before 35 weeks) or low birth weight $(<2.3 \mathrm{~kg})$, history of neurological disease, including chromosomal and active seizure disorders, use of prohibited medications (antianginal, antiarrhythmic, anticoagulant, antihypertensive, antineoplastic, diuretic, hypoglycemic or hypolipidemic agents; insulin; muscle relaxants; systemic antifungal agents or steroids; hormone suppressants; or psychotropic drugs. (Supplementary Table S2; Supplementary Data are available online at www.liebertpub.com/cap) and a primary psychiatric diagnosis other than autism. These exclusion criteria were also used for the OLEX trial. Post-menarcheal girls had to agree to use an investigator-approved method of contraception.
Written informed consents were collected from participants, when possible, and consents were obtained from the caregiver or from a parent, guardian, or legally authorized representative before the initiation of any study-specific procedures. The studies were reviewed and approved by the institutional review board at each site.

\section{Efficacy variables}

In MEM-MD-57A Part 2, the primary efficacy variable at endpoint was the change from baseline to Week 12 in the SRS total raw score (Constantino and Gruber 2005). The SRS is a 65 item instrument consisting of five subscales designed to assess social awareness, information processing, capacity for reciprocal response, anxiety/avoidance, and autistic preoccupations and traits. Each item is rated on a four point scale, with a higher score indicating greater impairment. The caregiver completed the SRS based on the patient's behavior over the previous 6 weeks at the beginning of the study (Baseline), Week 6, and Week 12 or at early termination of the study.

The secondary efficacy parameters were Core Autism Treatment Scale-Improvement (CATS-I) (a proprietary instrument, not yet validated) total score and subscales (social interaction and communication) at Week 12, and the change from baseline to Week 12 in 10 subscales of the Children's Communication Checklist-2 (CCC-2) (Bishop 2006). The CATS is a 14 item scale developed by the memantine autism research program team, which assesses social interaction (items 1-9) and communication (items 10-14). It consists of a severity component (CATS-S) administered at baseline and an improvement component (CATS-I) administered at every subsequent visit (Weeks 2, 4, 6, 8, 10, and 12). The subscales are scored from 1 to 7, with higher scores indicating greater impairment. The CCC-2 is a validated, norm-referenced, informantrated scale that assesses difficulties that affect communication (items 1-50) and strengths that may be demonstrated during communication (items 51-70). The 10 subscales are rated from 0 to 3 (higher scores indicate greater impairment) and assess speech, syntax, semantics, coherence, initiation, scripted language, context, nonverbal communication, social relations, and interests. The CCC-2 was administered at baseline and at Weeks 6 and 12.

Additional efficacy parameters included the Core and Associated Autism Symptom Treatment Scale (CAASTS) (a proprietary instrument, not yet validated, containing 23 items that test for stereotyped behaviors and restricted interests, associated maladaptive behaviors, and daily function), with a severity component (CAASTS-S) administered at baseline, and an improvement component (CAASTS-I) administered at every subsequent visit (Weeks 
2, 4, 6, 8, 10, and 12). The Clinical Global Impressions-Severity subscale (CGI-S) (Guy 1976) was administered at baseline and last visit, and the CGI Improvement subscale was administered at Weeks 2, 4, 6, 8, 10, and 12. The CGI scale was completed separately to evaluate the domains of social interaction, communication, integrated social interaction and communication, stereotyped behavior, restricted interests, associated maladaptive behaviors, and daily function. The ABC-C (Aman et al. 1985), was administered at baseline and at Weeks 6 and 12; and the Autism Health Economics and Outcomes Questionnaire (AHEOQ), developed by the sponsor, was also administered at baseline and at Weeks 6 and 12. The $\mathrm{ABC}-\mathrm{C}$ is a 58 item, informant-rated behavior rating scale with subscales assessing irritability ( 15 items; administered only at screening, to determine inclusion), stereotypy (7 items), hyperactivity (16 items), and inappropriate speech (4 items). The AHEOQ is designed to measure the direct and indirect financial burden of autism and to assess caregiver and family burden using a caregivercompleted questionnaire and two validated subscales: The Parenting Stress Index (Loyd and Abidin 1985) and the Health Utilities Index (Horsman, et al. 2003).

In the OLEX study, no efficacy parameters were considered primary. Additional efficacy variables were considered exploratory and included the SRS, CATS-I, CAASTS-I, CCC-2, CGI-S, CGI-I, and ABC-C. Efficacy assessments in the OLEX took place at the first visit and weeks $12,24,36,48$, and 60 , or early termination date.

\section{Safety and tolerability}

The safety population comprised all randomized participants who took at least one dose of the double-blind investigational product in MEM-MD-57A Part 2. The Part 2 autism safety population comprised all participants in the safety population who had autistic disorder and also met all of the Part 2 inclusion/exclusion criteria (i.e., participants from the PK studies who did not meet age or diagnostic criteria were not included in the autism safety population). Blood samples were drawn in all participants for PK analyses at Weeks 2, 4, and 12 or upon early termination, in order to confirm that actual AUC drug exposure was conforming to the predefined safety limit. In the OLEX study, blood samples for PK analyses were collected at Weeks 2, 24, and 48 or early termination. In both studies, vital signs were monitored at each clinic visit. A complete physical examination was performed at screening and the last visit. A standard 12 lead ECG and clinical laboratory tests (hematology, chemistry, and urinalysis) were performed at screening, baseline (excluding urine test), and the last visit or early termination; a urine drug screen was performed at Visit 1 only if deemed necessary by the investigator.

\section{Statistical analysis}

All efficacy analyses for MEM-MD-57A Part 2 were based on the autism intention-to-treat (ITT) population, which was defined as all randomized participants who satisfied Part 2 inclusion and exclusion criteria, took at least one dose of the double-blind medication, and had at least one postbaseline SRS measurement. Baseline was defined as the last nonmissing efficacy assessment on or before the date of the first dose of the investigational product. Unless stated otherwise, all statistical tests were two sided $(\alpha=0.05)$. The analysis of the primary and secondary efficacy parameters in MEM-MD-57A Part 2 was performed using a mixedeffects model with repeated measures (MMRM) that included treatment group, study center, visit, and treatment-by-visit inter- action as fixed effects and the baseline score and baseline-score-byvisit interaction as covariates based on the observed cases (OC). An unstructured covariance matrix was used to model covariance of within-patient scores. Two sensitivity analyses were also performed for the primary efficacy variable: One based on the last observation carried forward (LOCF) approach for imputing missing values and using an analysis of covariance (ANCOVA) model with treatment group and study center as the factors and baseline value as the covariate, and one using a pattern-mixture model based on non-future-dependent missing value restrictions (Kenward et al. 2003), performed to assess the robustness of the primary MMRM results to possible violation of the missing-at-random assumption. The secondary and additional efficacy variables were analyzed using an MMRM or an ANCOVA model, as indicated in the text, except for the CGI-I subscales, which were analyzed using a CochranMantel-Haenszel test with modified ridit scores, controlling for study center. In the OLEX (MEM-MD-67), efficacy parameters were analyzed using descriptive statistics based on the OC. SAS version 9.1.3 or newer (SAS Institute, Cary, NC) was used for all analyses. Safety parameters were analyzed using descriptive statistics.

\section{Results}

\section{Participants}

A total of 222 children were screened for the MEM-MD-57A Part 2 trial including 1 child who completed the MEM-MD-57A Part 1 trial, and 6 children who completed MEM-PK-21 (Fig. 2). Of the 121 children who enrolled in Part 2, 104 completed the trial (placebo: 82.0\%; memantine: 90.0\%) and 102 enrolled in the OLEX (Fig. 2). None of the seven children who entered MEM-MD57A Part 2 from Part 1 or from MEM-PK-21 were included in the autism ITT population (five because of absence of verbal fluency; two because they exceeded the prespecified age limit). The most common protocol deviations during MEM-MD-57A Part 2 were related to the use of prohibited concomitant medications (placebo: 27.9\%; memantine: $35.0 \%$ ); the most common categories of prohibited medications were antihistamines for systemic use (six in each group) and cough and cold preparations (placebo, $n=2$; memantine, $n=9)$. In Part 2, all six discontinuations (10.0\%) in the memantine arm occurred within the first 8 weeks of double-blind treatment, corresponding to the titration phase; in the placebo arm, seven participants $(11.5 \%$ ) discontinued treatment during Weeks 1-8 and four participants $(6.6 \%)$ discontinued after Week 8 . The completion rate in the OLEX was $64.7 \%$ (Fig. 2), and the most common protocol deviation was the use of prohibited concomitant medication (20.6\%); the most common prohibited medications were cough and cold preparations $(n=7)$ and methylphenidate $\mathrm{HCl}(n=4)$.

The demographic and clinical characteristics for both trials are summarized in Table 1. In MEM-MD-57A Part 2, the groups were well matched at baseline. The majority of participants were white males. Almost all participants $(90.9 \%)$ were in the two middle weight classes (groups B and C), weighing between 20 and $59 \mathrm{~kg}$. For MEM-MD-57A Part 2, the mean final daily dosages were $14.4 \mathrm{mg} /$ day, $8.3 \mathrm{mg} /$ day, $5.9 \mathrm{mg} /$ day, and $3.0 \mathrm{mg} /$ day for Groups A, B, C, and D, respectively, and for the OLEX, the mean final daily dose was $7.9 \mathrm{mg} /$ day.

\section{Efficacy}

Analysis of the change from baseline in SRS total raw score at Week 12 in MEM-MD-57A Part 2 showed no statistically significant difference between the treatment groups (least squares mean 


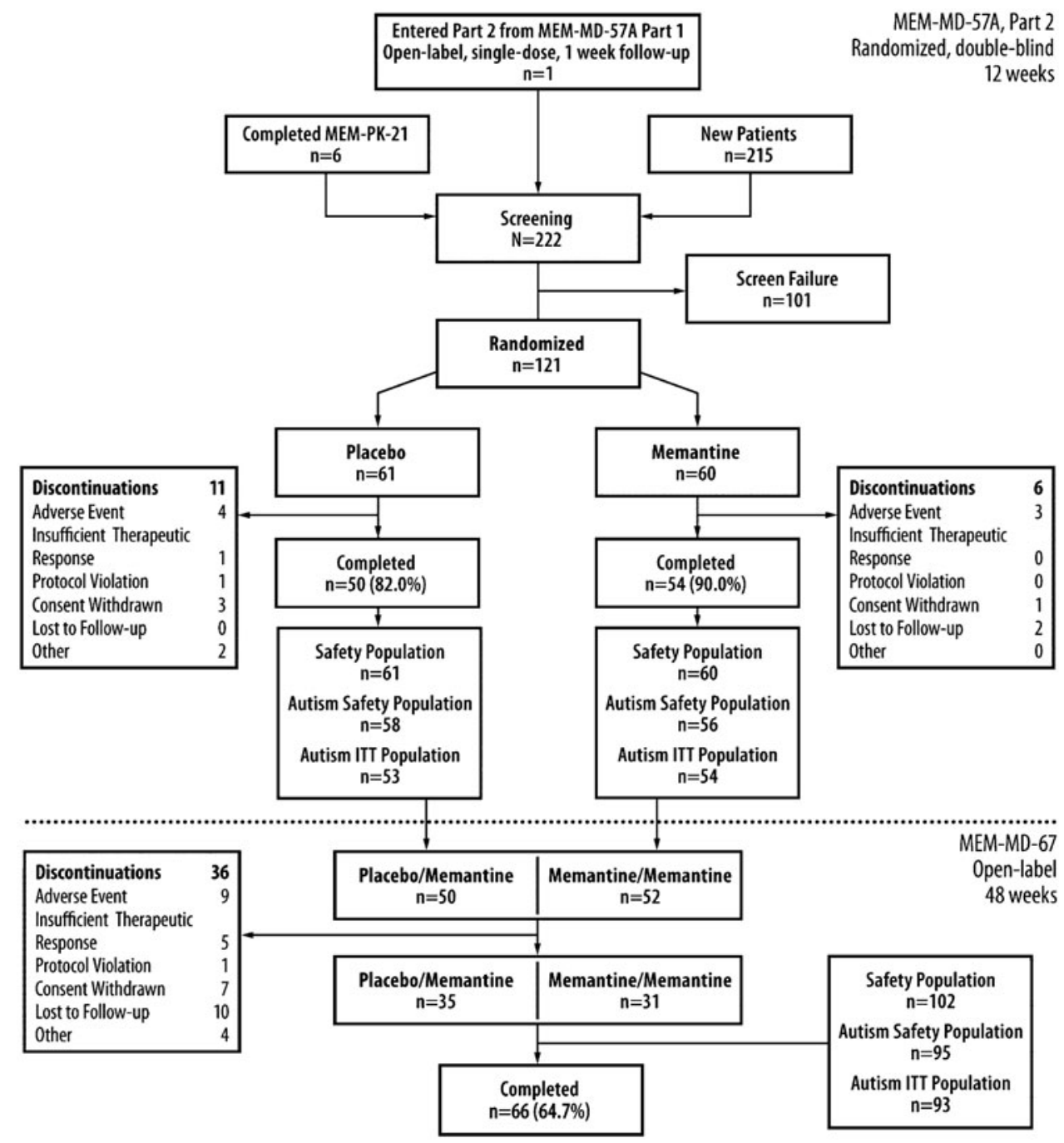

FIG. 2. Combined study flow for trials MEM-MD-57A (Part 1 and Part 2) and MEM-MD-67 (open-label extention [OLEX]). ITT indicates intention-to-treat. MEM-MD-57A Part 2 autism safety population: Subjects $(n=114)$ had only autistic disorder according to the Diagnostic and Statstical Manual of Mental Disorders, 4th ed., Text Revision (DSM-IV-TR). The larger safety population ( $n=121)$ included children with pervasive developmental disorder not otherwise specified (PDD-NOS) and/or Asperger's disorder.

difference [95\% confidence interval]: $-0.1[-7.2,6.6], p=0.978)$ (Fig. 3). Sensitivity analyses yielded similar results. (Analyses of SRS subscales also showed no significant between-group differences [data not shown].) However, at Week 12, both groups attained a clinically significant improvement from baseline of $\sim 10$ points (see Discussion). In the OLEX, the participants maintained an overall nominal improvement from Week 12 to the end of study of $\sim 6$ points, regardless of the previous treatment group assignment in MEM-MD-57A Part 2 (Fig. 3). From MEM-MD-57A Part 2 baseline to the end of the OLEX, there was an overall mean improvement of $\sim 15.6$ points in SRS total raw score for all study participants (Fig. 3).

There were no statistically significant between-group differences in CATS-I total or subscale scores at Week 12, but both groups demonstrated overall improvement versus baseline that was maintained or increased during the OLEX (Supplementary Fig. S1). In addition, there were no significant between-group differences on nine of the 10 CCC-2 subscales at Week 12; however, there was a significant difference favoring placebo in the context subscale $(p=0.02)$ (Fig. 4).
Finally, there were no statistically significant differences between the treatment groups on any of the additional efficacy measures.

\section{Safety and tolerability}

In the MEM-MD-57A Part 2 safety population, only one serious $\mathrm{AE}$ was reported; that of mood disorder (judged to be unrelated to the study medication) in a memantine ER-treated participant who was one of the few participants with ASD who did not meet the criteria for the diagnosis of autistic disorder. A total of seven participants discontinued treatment because of an $\mathrm{AE}$ (placebo, $n=4$ [6.6\%]; memantine, $n=3$ [5.0\%]) (Fig. 2). All treatment-emergent AEs (TEAEs) were mild or moderate in severity, except for three in the memantine group (irritability, affective disorder, choking); the occurrence of affective disorder in one participant was also considered a serious AE (SAE). TEAEs were experienced by 47 (77.0\%) placebo-treated and $51(85.0 \%)$ memantine ER-treated participants (Table 2); of those, $33(54.1 \%)$ and $36(60.0 \%)$, respectively, experienced a TEAE deemed related to study 
Table 1. Demographic and Clinical Characteristics at Baseline (Safety Population) ${ }^{a}$

\begin{tabular}{|c|c|c|c|c|}
\hline \multirow[b]{2}{*}{ Characteristic } & \multicolumn{2}{|c|}{ MEM-MD-57A Part 2 (Double-blind) } & \multicolumn{2}{|c|}{ MEM-MD-67 (Open-label extension) } \\
\hline & Placebo $(\mathrm{n}=61)$ & $\operatorname{Mem}(\mathrm{n}=60)$ & Placebo/Mem $(\mathrm{n}=50)$ & $\mathrm{Mem} / \mathrm{Mem}(\mathrm{n}=52)$ \\
\hline Age, years ${ }^{\mathrm{b}}$ & $8.9 \pm 2.2$ & $9.0 \pm 2.2$ & $9.1 \pm 2.3$ & $9.1 \pm 2.2$ \\
\hline Boys, $n(\%)$ & $49(80.3)$ & $52(86.7)$ & $41(82.0)$ & $46(88.5)$ \\
\hline \multicolumn{5}{|l|}{ Race, $n(\%)$} \\
\hline White & $49(80.3)$ & $50(83.3)$ & $42(84.0)$ & $44(84.6)$ \\
\hline Asian & $6(9.8)$ & $5(8.3)$ & $4(8.0)$ & $5(9.6)$ \\
\hline Black & $3(4.9)$ & $1(1.7)$ & $1(2.0)$ & $1(1.9)$ \\
\hline Other & $3(4.9)$ & $4(6.7)$ & $3(6.0)$ & $2(3.8)$ \\
\hline \multicolumn{5}{|c|}{ Weight group distribution, $n(\%)$} \\
\hline Group A $(\geq 60 \mathrm{~kg})$ & $4(6.6)$ & $5(8.3)$ & $\mathrm{n} / \mathrm{a}$ & $\mathrm{n} / \mathrm{a}$ \\
\hline Group B (40-59 kg) & $14(23.0)$ & $17(28.3)$ & $\mathrm{n} / \mathrm{a}$ & $\mathrm{n} / \mathrm{a}$ \\
\hline Group C (20-39 kg) & $42(68.9)$ & $37(61.7)$ & $\mathrm{n} / \mathrm{a}$ & $\mathrm{n} / \mathrm{a}$ \\
\hline Group D $(<20 \mathrm{~kg})$ & $1(1.6)$ & $1(1.7)$ & $\mathrm{n} / \mathrm{a}$ & $\mathrm{n} / \mathrm{a}$ \\
\hline \multicolumn{5}{|l|}{ Education Status, $n(\%)$} \\
\hline Public School & $48(78.7)$ & $48(80.0)$ & $\mathrm{n} / \mathrm{a}$ & $\mathrm{n} / \mathrm{a}$ \\
\hline Private School & $5(8.2)$ & $5(8.3)$ & $\mathrm{n} / \mathrm{a}$ & $\mathrm{n} / \mathrm{a}$ \\
\hline Home School & $1(1.6)$ & $2(3.3)$ & $\mathrm{n} / \mathrm{a}$ & $\mathrm{n} / \mathrm{a}$ \\
\hline Other & $6(9.8 \%)$ & $5(8.3)$ & $\mathrm{n} / \mathrm{a}$ & $\mathrm{n} / \mathrm{a}$ \\
\hline \multicolumn{5}{|l|}{ K-BIT2 score $^{\mathrm{b}}$} \\
\hline IQ composite & $75.7 \pm 19.4$ & $77.9 \pm 23.1$ & $75.9 \pm 19.8$ & $78.2 \pm 23.8$ \\
\hline Verbal score & $36.4 \pm 19.4$ & $37.0 \pm 16.2$ & $35.6 \pm 18.2$ & $37.4 \pm 16.3$ \\
\hline Nonverbal score & $32.1 \pm 26.1$ & $26.3 \pm 18.1$ & $31.6 \pm 25.8$ & $25.9 \pm 17.8$ \\
\hline \multicolumn{5}{|l|}{ ADOS Score ${ }^{b}$} \\
\hline Communication & $6.3 \pm 2.1$ & $6.3 \pm 2.2$ & $\mathrm{n} / \mathrm{a}$ & $\mathrm{n} / \mathrm{a}$ \\
\hline Social interaction & $11.0 \pm 2.8$ & $10.3 \pm 2.5$ & $\mathrm{n} / \mathrm{a}$ & $\mathrm{n} / \mathrm{a}$ \\
\hline Total & $17.3 \pm 4.5$ & $16.7 \pm 4.2$ & $\mathrm{n} / \mathrm{a}$ & $\mathrm{n} / \mathrm{a}$ \\
\hline SRS, Total Raw Score ${ }^{b, c}$ & $100.2 \pm 21.4$ & $101.3 \pm 25.2$ & $100.5 \pm 19.7$ & $102.2 \pm 25.5$ \\
\hline
\end{tabular}

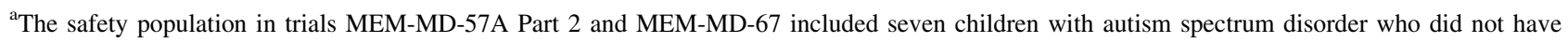
autism.

${ }^{\mathrm{b}}$ Mean \pm standard deviation.

${ }^{c}$ MEM-MD-57A Part 2: Autism ITT population (placebo, $n=53$, memantine, $n=54$ ); MEM-MD-67: Autism safety population (placebo/memantine, $n=46$; memantine/memantine, $n=47$ ).

ADOS, Autism Diagnostic Observation Schedule; IQ, intelligence quotient; K-BIT2, Kaufman Brief Intelligence Test, Version 2; Mem, extendedrelease memantine; SRS, Social Responsiveness Scale.

medication. The most common TEAEs that occurred in the memantine group at a higher incidence than in the placebo group were irritability $(6.7 \%$ vs. $3.3 \%)$ and aggression $(6.7 \%$ vs. $4.9 \%)$.

In the OLEX, one patient experienced an SAE (lobar pneumonia, deemed unrelated to treatment) and nine participants $(8.8 \%)$ discontinued because of TEAEs. Four participants $(3.9 \%)$ experienced five TEAEs that were considered severe (acne, acrodermatitis, pyrexia, and two cases of bronchitis) and also unrelated to the study medication. One TEAE (negativism), which was considered related to the treatment, resulted in the patient discontinuing treatment after 201 days. There were no PCS changes in ECG parameters. There were a few instances of PCS changes in laboratory parameters but none were associated with SAEs or AEs. The mean changes from baseline in laboratory values were generally small and not clinically meaningful (Supplementary Table S1).

The mean weight changes from baseline to Week 12 in MEMMD-57A, Part 2 were $0.9 \pm 2.0 \mathrm{~kg}$ (placebo) and $1.2 \pm 1.9 \mathrm{~kg}$ (memantine ER). Over the duration of MEM-MD-57A Part 2 and the OLEX, $66.3 \%$ of participants experienced at least $10 \%$ weight gain, whereas $7.6 \%$ of participants experienced at least $5 \%$ weight loss. Post-hoc analyses of the age-adjusted changes in body mass index and body weight category shift assessments indicated that most instances of weight gain were associated with children's growth (data not shown).

\section{Discussion}

This is the first report of a prospective, double-blind, randomized, placebo-controlled trial of memantine monotherapy in children with autism. In terms of efficacy, there was no statistically significant between-group difference on the primary efficacy measure, the SRS, at the completion of the randomized, double-blind phase (Week 12). Results from the 12 week and 48 week study periods indicate that both short-term and long-term treatments with memantine ER were well tolerated, with no emergent safety signals.

It may be of some interest that a potentially significant clinical improvement of 10 points on the SRS total raw score (according to the scale's author [Constantino JN, personal communication, 2012]) was observed after 12 weeks in both treatment groups, and that the SRS scores continued to improve numerically for the duration of the 48 week OLEX phase. This large placebo effect should not be surprising. In children with autism, randomized clinical trials using a variety of treatments have reported placebo response rates of 20-50\% (King et al. 2013), which could be attributed to several factors, including heightened expectation of parents and caregivers, 


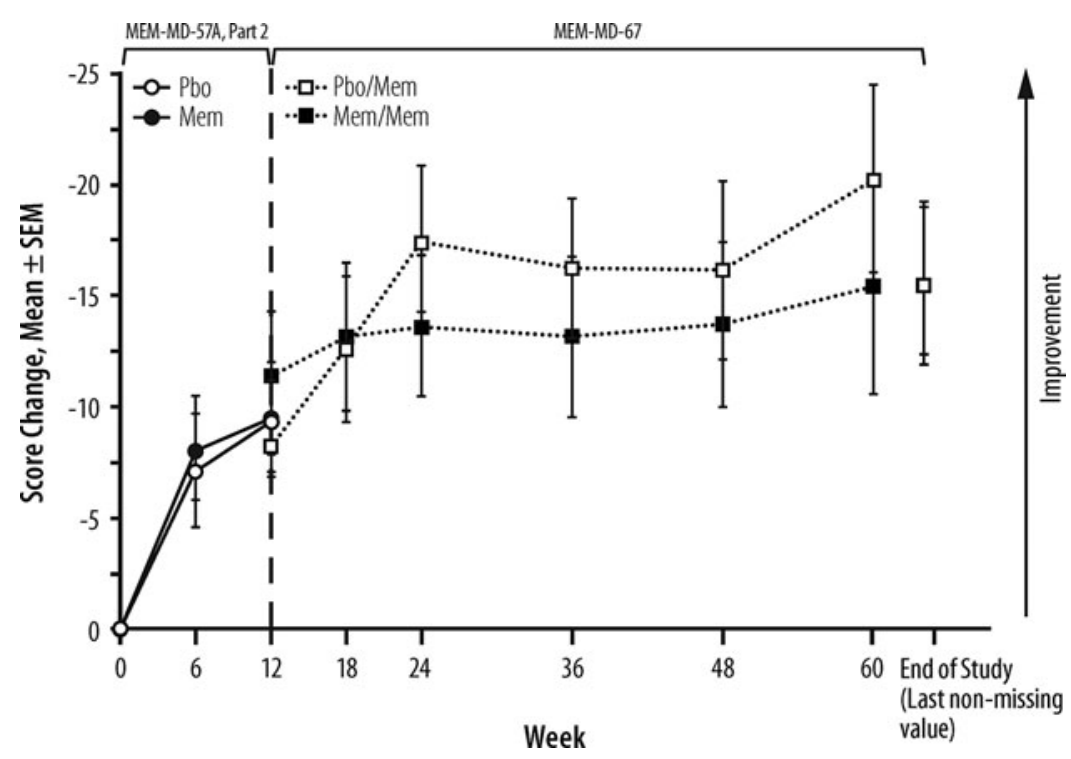

FIG. 3. Changes from baseline in Social Responsiveness Scale (SRS) total raw score (autism intent-to-treat [ITT] population). In the lead-in trial (MEM-MD-57A Part 2), mixed-effects model with repeated measures (MMRM) approach based on observed cases was performed, and in the open-label extention (OLEX) study (MEM-MD-67) only descriptive statistics were analyzed; therefore, the presented changes from baseline are least squares means from the MMRM model for MEM-MD-57A Part 2, and ordinary means for MEM-MD-67. Mem, extended-release memantine; Pbo, placebo; SEM, standard error of the mean.

waxing and waning of symptoms, and positive response to the attention and structure inherent to clinical trials (Sandler 2005). In one trial, children who were more symptomatic in composite measures of disruptive behavior, autism/mood, and caregiver strain at baseline were found to be less likely to respond to placebo (King et al. 2013), which suggests that the level of baseline symptomatology should be considered in the design and interpretation of future trials in ASD.

Further limitations of the current studies may include the potential lack of sensitivity of the scale used to assess real improvement, the absence of a biological marker that would allow correlation of any clinical improvement with biological changes, and the heterogeneity of ASD symptoms. In addition, numerous outcome measures were used, and some of them had not been validated or tested in previous randomized controlled trials.

We were intrigued by the suggestion of improvement shown by the placebo-treated participants who started receiving memantine ER during OLEX MEM-MD-67 (Fig. 3 and Supplementary Fig. S1), especially between treatment weeks 18 and 36 . Although a post-hoc statistical assessment indicated that this improvement was not statistically significant compared with the memantine-memantine sequence, the observation of a potential signal may inform future strategies for testing the efficacy in regard to core symptoms of ASD. For example, it is possible that up to 18 weeks are needed to eliminate the hope and expectation that accompany participation in a trial such as this one.

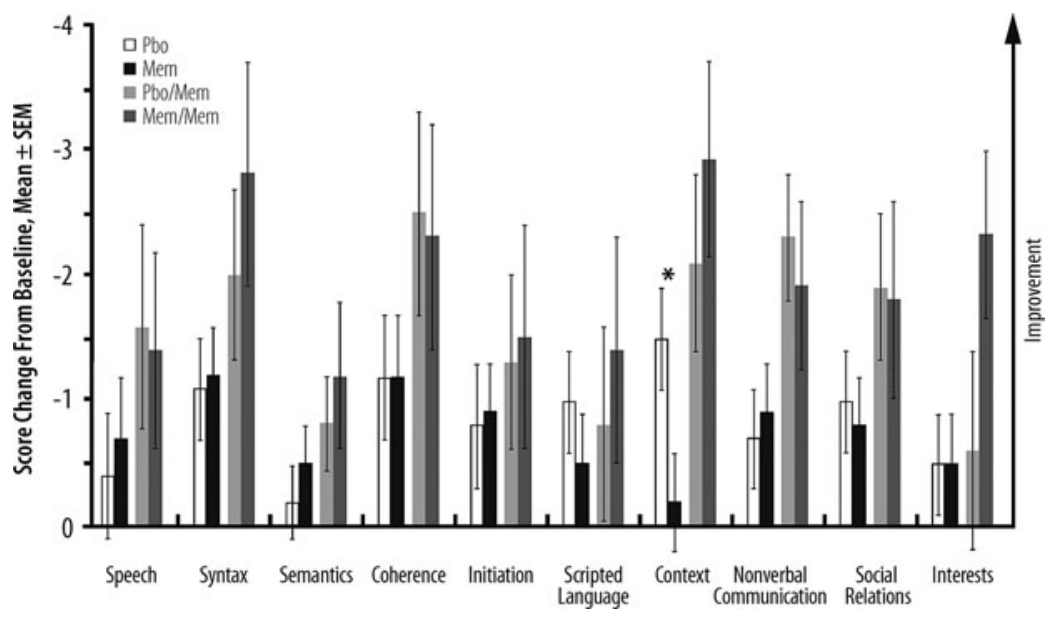

FIG. 4. Score changes from baseline at Week 12 (MEM-MD-57A Part 2: Pbo, Mem) and Week 60 or end of study (MEM-MD-67: $\mathrm{Pbo} / \mathrm{Mem}, \mathrm{Mem} / \mathrm{Mem}$ ) in Children's Communication Checklist, 2nd ed. (CCC-2) Subscales (autism intent-to-treat [ITT] population). In MEM-MD-57A Part 2 the mixed-effect model repeated measures (MMRM) approach based on observed cases was performed, and in MEM-MD-67 only descriptive statistics were analyzed. Therefore, the score changes from baseline are least squares means from MMRM model for MEM-MD-57A Part 2 and ordinary means for MEM-MD-67. ${ }^{*} p=0.02$. Mem, extended-release memantine; Pbo, placebo; SEM, standard error of the mean. 
Table 2. Trials MEM-MD-57A Part 2 and MEM-MD-67: Common TEAEs (Safety Population), $N(\%)$

\begin{tabular}{|c|c|c|c|}
\hline \multirow[b]{2}{*}{ TEAE } & \multicolumn{2}{|c|}{ MEM-MD-57A Part 2 (12 Weeks) } & \multirow{2}{*}{$\frac{M E M-M D-67(48 \text { Weeks })}{\operatorname{Mem}(\mathrm{n}=102)}$} \\
\hline & Placebo $(\mathrm{n}=61)$ & $\operatorname{Mem}(\mathrm{n}=60)$ & \\
\hline Any TEAE & $47(77.0)$ & $51(85.0)$ & $85(83.3)$ \\
\hline \multicolumn{4}{|c|}{ TEAEs with incidence $\geq 3 \%$ in either group in trial MEM-MD-57A, Part 2} \\
\hline Upper respiratory tract infection & $7(11.5)$ & $6(10.0)$ & $15(14.7)$ \\
\hline Cough & $3(4.9)$ & $6(10.0)$ & $10(9.8)$ \\
\hline Irritability & $3(4.9)$ & $5(8.3)$ & $7(6.9)$ \\
\hline Aggression & $3(4.9)$ & $5(8.3)$ & $8(7.8)$ \\
\hline Vomiting & $6(9.8)$ & $4(6.7)$ & $8(7.8)$ \\
\hline Insomnia & $3(4.9)$ & $4(6.7)$ & $8(7.8)$ \\
\hline Influenza & $2(3.3)$ & $4(6.7)$ & $5(4.9)$ \\
\hline Agitation & $1(1.6)$ & $4(6.7)$ & $6(5.9)$ \\
\hline Headache & $3(4.9)$ & $3(5.0)$ & $7(6.9)$ \\
\hline Rhinorrhea & 0 & $3(5.0)$ & $3(2.9)$ \\
\hline Nasopharyngitis & $6(9.8)$ & $2(3.3)$ & $7(6.9)$ \\
\hline Pyrexia & $4(6.6)$ & $2(3.3)$ & $6(5.9)$ \\
\hline Diarrhea & $3(4.9)$ & $2(3.3)$ & $5(4.9)$ \\
\hline Ear infection & $1(1.6)$ & $2(3.3)$ & $5(4.9)$ \\
\hline Laceration & $1(1.6)$ & $2(3.3)$ & 0 \\
\hline Rhinitis, allergic & $1(1.6)$ & $2(3.3)$ & $5(4.9)$ \\
\hline Stereotypy & $1(1.6)$ & $2(3.3)$ & $5(4.9)$ \\
\hline Affective disorder & 0 & $2(3.3)$ & $1(1.0)$ \\
\hline Enuresis & 0 & $2(3.3)$ & $2(2.0)$ \\
\hline Frequent bowel movements & 0 & $2(3.3)$ & $1(1.0)$ \\
\hline Nasal congestion & $5(8.2)$ & $1(1.7)$ & $8(7.8)$ \\
\hline Psychomotor hyperactivity & $4(6.6)$ & $1(1.7)$ & $6(5.9)$ \\
\hline Abdominal pain, upper & $3(4.9)$ & $1(1.7)$ & $4(3.9)$ \\
\hline Oropharyngeal pain & $3(4.9)$ & $1(1.7)$ & $2(2.0)$ \\
\hline Abnormal behavior & $2(3.3)$ & $1(1.7)$ & $1(1.0)$ \\
\hline Nausea & $2(3.3)$ & $1(1.7)$ & $2(2.0)$ \\
\hline Anxiety & $4(6.6)$ & 0 & $4(3.9)$ \\
\hline Seasonal allergy & $3(4.9)$ & 0 & $9(8.8)$ \\
\hline Abdominal pain & $2(3.3)$ & 0 & $1(1.0)$ \\
\hline Nosebleed (epistaxis) & $2(3.3)$ & 0 & $3(2.9)$ \\
\hline \multicolumn{4}{|c|}{ Additional TEAEs, with occurrence $\geq 3 \%$ in trial MEM-MD-67 } \\
\hline Weight increased ${ }^{\mathrm{a}}$ & 0 & 0 & $9(8.8)$ \\
\hline Constipation & $1(1.6)$ & $1(1.7)$ & $7(6.9)$ \\
\hline Initial insomnia & $1(1.6)$ & $1(1.7)$ & $4(3.9)$ \\
\hline Pharyngitis, streptococcal & 0 & $1(1.7)$ & $4(3.9)$ \\
\hline
\end{tabular}

${ }^{\text {a }}$ Post-hoc analyses of age-adjusted changes in body weight indicates that most instances of weight gain in the trial MEM-MD-67 were associated with children's growth (data not shown).

TEAE categories are ordered by decreasing incidence in the memantine group.

Mem, extended-release memantine; TEAE, treatment-emergent adverse event.

The only other randomized trial of memantine in children with ASD was conducted in risperidone-treated children with autism. This trial showed significant benefits of add-on memantine versus add-on placebo on the $\mathrm{ABC}$ irritability subscale after 10 weeks of treatment (Ghaleiha et al. 2013). However, the study is difficult to compare with ours not only because of the background antipsychotic treatment and different primary efficacy parameter (the ABC), but also because the selection criteria for our trial precluded participation of children with prominent irritability symptoms (see Methods).

\section{Conclusions and Clinical Significance}

In this study, there was no evidence of memantine ER efficacy at the dosages used on core symptoms of autism. The treatment was shown to be safe and well tolerated at the dosages examined: there were no emergent laboratory or ECG concerns, and elevated irritability and agitation (which have been reported in some smaller studies) failed to emerge as significant issues. A good safety profile and a strong placebo effect keep the possibility open that memantine ER could be a viable therapeutic option for other conditions affecting children. That, however, remains to be proven in prospective randomized trials.

\section{Acknowledgments}

Editorial assistance (data verification, coordination of drafts, development of tables and figures, formatting for submission) was provided by Jonathan Kelley, Biplob Dass, and Vojislav Pejović, of Prescott Medical Communications Group (Chicago, IL), a contractor of the study sponsor.

\section{Authors' Contributions}

Data were analyzed by Dr. Hsu. First draft of the manuscript was co-authored by Drs. Aman and Katz. All authors revised the manuscript critically and approved the final version for submission. 


\section{Disclosures}

In the past 36 months, Dr. Aman received research contracts from, consulted with, served on advisory boards of, or performed investigator training for Biomarin Pharmaceuticals, Bristol-Myers Squibb, CogState, Inc., CogState Clinical Trials, Ltd., Confluence Pharmaceutica, Coronado Biosciences, Forest Research Institute, Hoffman-La Roche, Janssen Pharmaceuticals, Johnson \& Johnson, Lumos Pharma, MedAvante, Inc., Novartis, Pfizer, ProPhase LLC, and Supernus Pharmaceuticals. Dr. Findling receives or has received research support from, or acted as a consultant and/or served on a speaker's bureau for Alcobra, American Academy of Child \& Adolescent Psychiatry, American Physician Institute, American Psychiatric Press, AstraZeneca, Bracket, Bristol-Myers Squibb, CogCubed, Cognition Group, Coronado Biosciences, Dana Foundation, Elsevier, Forest, GlaxoSmithKline, Guilford Press, Johns Hopkins University Press, Johnson and Johnson, Jubilant Clinsys, KemPharm, Lilly, Lundbeck, Merck, NIH, Neurim, Novartis, Noven, Otsuka, Oxford University Press, Pfizer, Physicians Postgraduate Press, Purdue, Rhodes Pharmaceuticals, Roche, Sage, Shire, Sunovion, Supernus Pharmaceuticals, Transcept Pharmaceuticals, Validus, and WebMD. Dr. Hardan previously received research funding from Forest; he has no current conflicts of interest to disclose. Dr. Hendren received research grants from Autism Speaks, BioMarin Pharmaceuticals, Curemark, Forest, Roche, Shire, Sunovion, and the Vitamin D Council; is on Advisory Boards for BioMarin Pharmaceuticals, Forest, Janssen, and Neuren; and is a reviewer for Autism Speaks, Brain Canada, and Simons Foundation. Dr. Melmed received research support from Alcobra, Bristol-Myers Squibb Company, Forest Laboratories Inc, Neurim, Novartis Pharmaceuticals, Roche Pharmaceuticals, and Seaside Pharmaceuticals during the past year. Ms. Kehinde-Nelson, and Drs. Hsu, Trugman, Palmer, Graham, Gage, Perhach, and Katz were employees of the study sponsor at the time of the study and are present or former stockholders of Forest (now Allergan). Dr. Trugman is currently an employee of the study sponsor.

\section{References}

Aman MG, Singh NN, Stewart AW, Field CJ: The Aberrant Behavior Checklist: A behavior rating scale for the assessment of treatment effects. Am J Ment Defic 89:485-491, 1985.

American Psychiatric Association: Diagnostic and Statistical Manual of Mental Disorders, 4th ed., Text Revision. Washington, DC: American Psychiatric Association; 2000.

Bauman ML, Kemper TL: Neuroanatomic observations of the brain in autism: A review and future directions. Int J Dev Neurosci 23:183$187,2005$.

Bishop DVM: Children's Communication Checklist-2 (CCC-2) US Edition (Manual). San Antonio: Harcourt Assessments, Inc.; 2006.

Blue ME, Naidu S, Johnston MV: Development of amino acid receptors in frontal cortex from girls with Rett syndrome. Ann Neurol 45:541-545, 1999.

Chez MG, Burton Q, Dowling T, Chang M, Khanna P, Kramer C: Memantine as adjunctive therapy in children diagnosed with autistic spectrum disorders: An observation of initial clinical response and maintenance tolerability. J Child Neurol 22:574-579, 2007.

Choudhury PR, Lahiri S, Rajamma U: Glutamate mediated signaling in the pathophysiology of autism spectrum disorders. Pharmacol Biochem Behav 100:841-849, 2012.

Collingridge GL, Watkins JC: The NMDA Receptor, 2nd ed. Oxford, New York: Oxford University Press; 1994.
Constantino JN, Gruber CP: The Social Responsiveness Scale (SRS) (Manual). Los Angeles: Western Psychological Services; 2005.

Curran MP: Aripiprazole: In the treatment of irritability associated with autistic disorder in pediatric patients. Paediatr Drugs 13:197204, 2011.

Danysz W, Parsons CG: Alzheimer's disease, beta-amyloid, glutamate, NMDA receptors and memantine-searching for the connections. Br J Pharmacol 167:324-352, 2012.

Elsabbagh M, Divan G, Koh YJ, Kim YS, Kauchali S, Marcin C, Montiel-Nava C, Patel V, Paula CS, Wang C, Yasamy MT, Fombonne E: Global prevalence of autism and other pervasive developmental disorders. Autism Res 5:160-179, 2012.

Erickson CA, Posey DJ, Stigler KA, Mullett J, Katschke AR, McDougle CJ: A retrospective study of memantine in children and adolescents with pervasive developmental disorders. Psychopharmacology (Berl) 191:141-147, 2007.

Fatemi SH, Halt AR, Stary JM, Kanodia R, Schulz SC, Realmuto GR: Glutamic acid decarboxylase 65 and $67 \mathrm{kDa}$ proteins are reduced in autistic parietal and cerebellar cortices. Biol Psychiatry 52:805810, 2002.

Findling RL, McNamara NK, Stansbrey RJ, Maxhimer R, Periclou A, Mann A, Graham SM: A pilot evaluation of the safety, tolerability, pharmacokinetics, and effectiveness of memantine in pediatric patients with attention-deficit/hyperactivity disorder combined type. J Child Adolesc Psychopharmacol 17:19-33, 2007.

Fombonne E: Epidemiology of pervasive developmental disorders. Pediatr Res 65:591-598, 2009.

Ghaleiha A, Asadabadi M, Mohammadi MR, Shahei M, Tabrizi M, Hajiaghaee R, Hassanzadeh E, Akhondzadeh S: Memantine as adjunctive treatment to risperidone in children with autistic disorder: A randomized, double-blind, placebo-controlled trial. Int J Neuropsychopharmacol 16:783-789, 2013.

Gotham K, Risi S, Dawson G, Tager-Flusberg H, Joseph R, Carter A, Hepburn S, McMahon W, Rodier P, Hyman SL, Sigman M, Rogers S, Landa R, Spence MA, Osann K, Flodman P, Volkmar F, Hollander E, Buxbaum J, Pickles A, Lord C: A replication of the Autism Diagnostic Observation Schedule (ADOS) revised algorithms. J Am Acad Child Adolesc Psychiatry 47:642-651, 2008.

Guy W: Clinical Global Impressions. In: ECDEU Assessment Manual for Psychopharmacology (Revised). Edited by W. Guy. Rockville, MD, U.S. Department of Health, Education, and Welfare, Public Health Service, Alcohol, Drug Abuse, and Mental Health Administration, National Institute of Mental Health, Psychopharmacology Research Branch, Division of Extramural Research Programs; 1976; pp. 218-222.

Horsman J, Furlong W, Feeny D, Torrance G: The Health Utilities Index (HUI): Concepts, measurement properties and applications. Health Qual Life Outcomes 1:54, 2003.

Kenward M, Molenberghs G, Thijs H: Pattern-mixture models with proper time dependence. Biometrika 90:53-71, 2003.

King BH, Dukes K, Donnelly CL, Sikich L, McCracken JT, Scahill L, Hollander E, Bregman JD, Anagnostou E, Robinson F, Sullivan L, Hirtz D: Baseline factors predicting placebo response to treatment in children and adolescents with autism spectrum disorders: Multisite randomized clinical trial. JAMA Pediatr 167:1045-1052, 2013.

Lord C, Rutter M, Le Couteur A: Autism Diagnostic InterviewRevised: A revised version of a diagnostic interview for caregivers of individuals with possible pervasive developmental disorders. J Autism Dev Disord 24:659-685, 1994.

Loyd BH, Abidin RR: Revision of the Parenting Stress Index. J Pediatr Psychol 10:169-177, 1985.

McCracken JT, McGough J, Shah B, Cronin P, Hong D, Aman MG, Arnold LE, Lindsay R, Nash P, Hollway J, McDougle CJ, Posey D, 
Swiezy N, Kohn A, Scahill L, Martin A, Koenig K, Volkmar F, Carroll D, Lancor A, Tierney E, Ghuman J, Gonzalez NM, Grados M, Vitiello B, Ritz L, Davies M, Robinson J, McMahon D: Research Units on Pediatric Psychopharmacology Autism Network: Risperidone in children with autism and serious behavioral problems. N Engl J Med 347:314-321, 2002.

Mohiuddin S, Ghaziuddin M: Psychopharmacology of autism spectrum disorders: A selective review. Autism 17:645-654, 2013.

Moreno-Fuenmayor H, Borjas L, Arrieta A, Valera V, SocorroCandanoza L: Plasma excitatory amino acids in autism. Invest Clin 37:113-128, 1996.

Namenda XR: Prescribing Information. Dublin, Ireland: Forest Pharmaceuticals; 2010.

Owley T, Salt J, Guter S, Grieve A, Walton L, Ayuyao N, Leventhal BL, Cook EH, Jr.: A prospective, open-label trial of memantine in the treatment of cognitive, behavioral, and memory dysfunction in pervasive developmental disorders. J Child Adolesc Psychopharmacol 16:517-524, 2006.

Purcell AE, Jeon OH, Zimmerman AW, Blue ME, Pevsner J: Postmortem brain abnormalities of the glutamate neurotransmitter system in autism. Neurology 57:1618-1628, 2001.

Rosenberg RE, Daniels AM, Law JK, Law PA, Kaufmann WE: Trends in autism spectrum disorder diagnoses: 1994-2007. J Autism Dev Disord 39:1099-1111, 2009.

Rossi J, Newschaffer C, Yudell M: Autism spectrum disorders, risk communication, and the problem of inadvertent harm. Kennedy Inst Ethics J 23:105-138, 2013.
Sandler A: Placebo effects in developmental disabilities: implications for research and practice. Ment Retard Dev Disabil Res Rev 11:164-170, 2005.

Tocco M, Bayles K, Lopez OL, Hofbauer RK, Pejović V, Miller ML, Saxton J: Effects of memantine treatment on language abilities and functional communication: A review of data. Aphasiology 28:236257, 2014.

United States Food and Drug Administration: Guidance for Industry E11. Clinical Investigation of Medicinal Products in the Pediatric Population. Rockville, MD: Food and Drug Administration, Center for Drug Evaluation and Research, Center for Biologies Evaluation and Reasearch; 2000.

Wenk GL, O'Leary M, Nemeroff CB, Bissette G, Moser H, Naidu S: Neurochemical alterations in Rett syndrome. Brain Res Dev Brain Res 74:67-72, 1993.

Yudell M, Tabor HK, Dawson G, Rossi J, Newschaffer C: Priorities for autism spectrum disorder risk communication and ethics. Autism 17:701-722, 2013.

Address correspondence to: Michael Aman, PhD The Nisonger Center UCEDD Ohio State University 1581 Dodd Drive Columbus, $\mathrm{OH} 43210-1257$

E-mail: aman.1@osu.edu 